\title{
Do ankle brachial index and pulse volume waveforms compare with the Ultrasound Duplex Scan for identifying Peripheral Arterial Disease?
}

\author{
Jane Lewis \\ From 2014 College of Podiatry Conference and Exhibition \\ Bournemouth, UK. 13-15 November 2014
}

\section{Aims/Objectives}

To compare the sensitivity, specificity and overall accuracy of an automated ankle-brachial index (ABI) and pulse volume waveform (PVR) with the Ultrasound Duplex Scan (UDS) for identifying Peripheral Arterial Disease (PAD).

\section{Content of presentation}

200 patients referred for UDS of lower limb arteries at two Medical Physics departments in the UK underwent an automated ABI and PVR measurement using a device utilising volume plethysmography followed by a UD Scan. PAD was recorded for automated ABI if $<0.9$ (and noted if $>1.30$ ), PVR's if graded mild/moderate/severe and with a haemodynamically significant stenosis or occlusive disease with the UDS. A result of PAD or NO PAD was recorded for each patient and each method. The outcome measure for this study was the agreement and overall accuracy between the automated ABI and UDS results and the PVR and UDS results.

\section{Relevance/Impact}

Of the 200 patients recruited $65 \%$ were male, $35 \%$ female with an overall mean age of 67 years (range 25-90 (SD 12.38)). 26.7\% had DM, 36.7\% had CHD, and $28.9 \%$ were smokers. 38\% were found to have PAD using the gold standard UDS. Those with DM and PAD $=7 \%$, CHD and $\mathrm{PAD}=15 \%$ and smokers with $\mathrm{PAD}=16.4 \%$. The overall results indicated good agreement between ABI and UDS (sensitivity $85 \%$, specificity $89 \%$ with overall accuracy $88 \%$ ) and between PVR and UDS (sensitivity $97 \%$, specificity of $89 \%$, with overall accuracy $95 \%$ ).

Cardiff and Vale University Health Board, Cardiff Metropolitan University, UK

\section{Discussions}

The combined use of the ABI and PVR within one device could enhance vascular assessment especially those with potentially calcified vessels and for treatment planning of leg and foot wounds. With its rapid assessment time, it also has the potential to be introduced into a primary care screening environment as a reliable tool for confirming symptomatic PAD and early identification of asymptomatic PAD.

Published: 20 April 2015

doi:10.1186/1757-1146-8-S1-A11

Cite this article as: Lewis: Do ankle brachial index and pulse volume waveforms compare with the Ultrasound Duplex Scan for identifying Peripheral Arterial Disease? Journal of Foot and Ankle Research 20158 (Suppl 1):A11.
Submit your next manuscript to BioMed Central and take full advantage of:

- Convenient online submission

- Thorough peer review

- No space constraints or color figure charges

- Immediate publication on acceptance

- Inclusion in PubMed, CAS, Scopus and Google Scholar

- Research which is freely available for redistribution
() Biomed Central 